\title{
Selected physicochemical properties of amniotic fluid according to week of pregnancy
}

\author{
Velika B ${ }^{1}$, Birkova $\mathrm{A}^{1}$, Dudic $\mathrm{R}^{2}$, Urdzik $\mathrm{P}^{2}$, Marekova $\mathrm{M}^{1}$ \\ Department of Medical and Clinical Biochemistry; Faculty of Medicine, PJS University in Kosice, \\ Kosice, Slovakia. beata.velika@upjs.sk
}

\begin{abstract}
BACKGROUND: A hundred years ago, scientists believed that amniotic fluid is a yellowish hypotonic mixture of foetal urine and maternal transudate with peculiar odour. Current knowledge shows that it represents a dynamic, complex mixture of inorganic and organic compounds.

OBJECTIVES: Despite modern technological procedures, information is still lacking about the composition and properties of amniotic fluid. We focused on dynamics of selected physical and chemical properties of the amniotic fluid with the increasing gestational week.

METHODS: The physicochemical characteristics of 89 amniotic fluid samples were determined according to the week of pregnancy. The determination of $\mathrm{pH}$, specific gravity, glucose and nitrites was performed immediately, at room temperature.

RESULTS: Our results show a significant negative correlation between week of pregnancy and semi-quantitative determined parameters of specific gravity $(p<0.001), \mathrm{pH}(p<0.01)$ and glucose $(p<0.001)$ values. Within the whole group of samples ( $(n=89), 29 \%(n=26)$ were nitrites positive $(N+)$ and $71 \%(n=63)$ nitrites negative $(N-)$. CONCLUSION: In this study were determined basic parameters of amniotic fluid, which could be related to a wide range of pathological states (Tab. 2, Fig. 1, Ref. 27). Text in PDF www.elis.sk.

KEY WORDS: amniotic fluid, gestational week, physicochemical properties, pregnancy.
\end{abstract}

\section{Introduction}

Amniotic fluid (AF) is a complex of essential substances necessary for foetal well-being. It contains nutrients and growth factors that facilitate foetal growth; it provides the foetus with foetal nutrients, mechanical cushioning and antimicrobial protection (antimicrobial peptides against common bacterial and fungal pathogens) and enables the assessment of foetal maturity and disease $(1,2)$. AF represents a relatively stagnant pool, circulating with a turnover time of approximately one day (3). Approximately 98 - $99 \%$ of AF is water, but it also contains electrolytes, proteins, peptides, carbohydrates, lipids and hormones. During the first trimester, the composition of AF is similar to that of foetal plasma, because the skin of the foetus is not keratinized, and together with the placenta and umbilical cord it is freely permeable to water and solutes (4). By the 8th week of gestation in humans, the urethra is formed and the foetal kidneys start to produce urine (the kidneys themselves start to develop during the 4th and 5th weeks). The low AF osmolarity, which is produced by the inflow of markedly

${ }^{1}$ Department of Medical and Clinical Biochemistry; Faculty of Medicine, PJS University in Kosice, Kosice, Slovakia, and ${ }^{2}$ Department of Gynaecology and Obstetrics, Louis Pasteur University Hospital, Kosice, Slovakia

Address for correspondence: B. Velika, RND, PhD, Department of Medical and Clinical Biochemistry, Faculty of Medicine, PJS University in Kosice, Trieda SNP 1, SK-040 11 Kosice, Slovakia.

Phone: +421.55.2343226 hypotonic foetal urine, provides a large potential osmotic force for the outward flow of water across the intramembranous and transmembranous pathways (3). AF is an excellent source of material for research; the chemical composition of its substances varies with gestational age, it is connected with different biochemical functions and is a part of several metabolic processes in the body. Therefore, it is important in the study of foetal development, foetal well-being and antenatal diagnosis while it can provide clues for new biomarkers and therapeutic targets. The assessment of AF is also helpful in the prenatal diagnosis of neural tube defects and an impressive array of inborn errors of metabolism and hematologic and genetic diseases (1).

\section{Material and methods}

AF samples from 89 women (16th-40th gestation weeks) with no visible traces of blood were obtained by amniocentesis, and samples towards the end of pregnancy were taken during a C-section. Samples of human AF were obtained by amniocentesis at the Department of Gynaecology and Obstetrics, Louis Pasteur University Hospital in Košice, Slovakia. Participation in the present study was fully voluntary. Detailed information about the study and its procedures was given to all respondents, and informed consent was obtained prior to medical examination. All clinical investigations were conducted according to the declaration of Helsinki principles. The indication for amniocentesis in the earliest weeks was advanced maternal age or a positive serum screening 

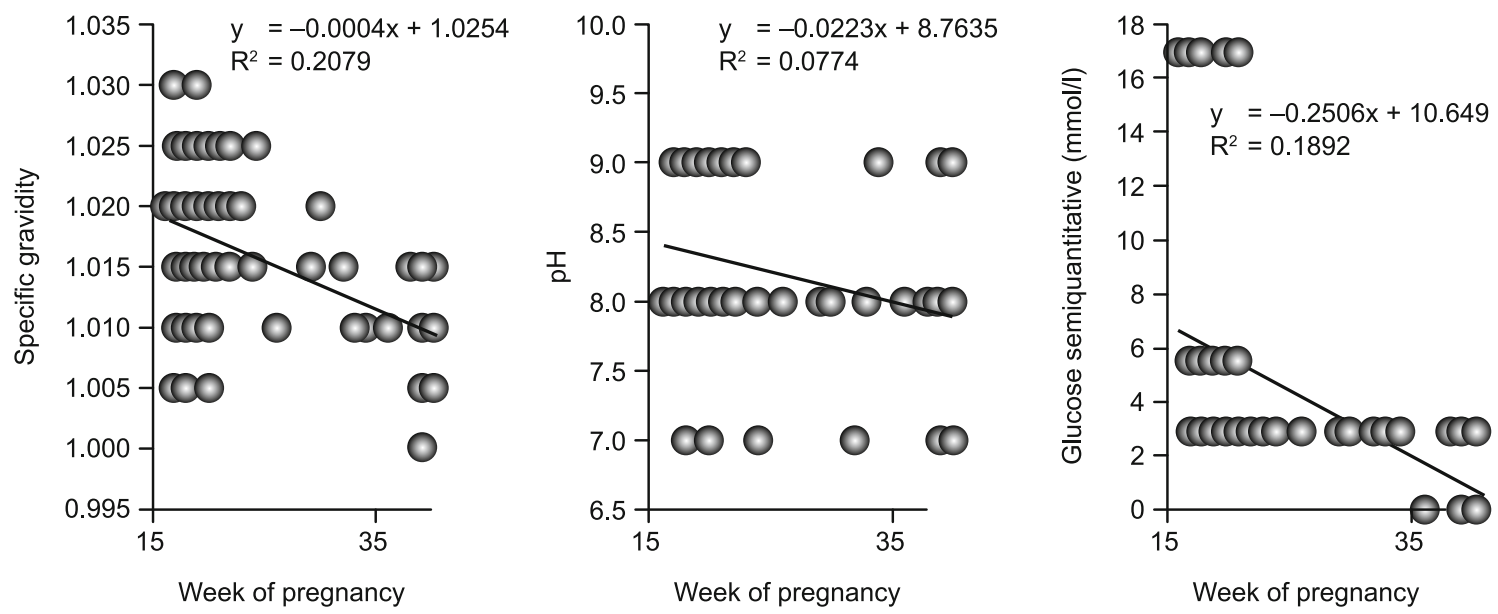

Fig. 1. Correlation between the week of pregnancy and semi-quantitatively determined parameters within the whole group.

test result. Patients were informed by their doctor about the use of their AF for experimental and diagnostic purposes. Informed consent was signed.

The determination of $\mathrm{pH}$, specific gravity, glucose and nitrites was performed immediately by using diagnostic strips at room temperature. Specific gravity was determined on the principle based on the ion exchange, which runs between polyelectrolyte and ions in body fluid. The test for glucose determination is based on the specific glucose oxidase/peroxidase reaction and is specific for D-glucose and semi-quantitatively corresponds to glucose concentrations of 2.8/5.5/17 and $55 \mathrm{mmol} / \mathrm{l}$. The test for nitrite determination is a colour test based on the principle of the Griess test.

\section{Statistical analysis}

For all obtained data, the Pearson correlation analysis, simple linear regression or unpaired T-test was used. All data are reported as means \pm SD and the range of measured levels.

\section{Results}

The file consists of 89 patients, of whom 68 were subdued to amniocentesis performed up to 24 weeks of pregnancy; 21 samples of amniotic fluid were collected from patients in the third trimester, of which 14 were at term. Indication of amniocentesis (age/ positive triple test/ultrasound) has no impact on the values of the observed parameters ( $\mathrm{pH}$, specific gravity, glucose, nitrites). For the whole group, the established values were: $\mathrm{pH}: 7-9$ (8.25 \pm $0.64)$, specific gravity: $1-1.03(1.016 \pm 0.0071)$, and glucose: 0 $-17 \mathrm{mmol} / \mathrm{l}(4.84 \pm 4.64 \mathrm{mmol} / \mathrm{l})$. The results show a significant negative correlation between the week of pregnancy and semiquantitatively determined parameters of specific gravity (SG), $\mathrm{pH}$ and glucose (Glu) values (Fig. 1, Tab. 1). High glucose concentration is associated with higher $\mathrm{pH}$ values $(\mathrm{r}=0.33$; $\mathrm{p}=0.0015)$.

Different results were obtained after dividing the total group into sub-groups of samples taken in the 2nd and 3rd trimesters of gestation. For the 2nd trimester, average values of SG, $\mathrm{pH}$ and glucose were $1.02 \pm 0.0066,8.34 \pm 0.61$ and $5.84 \pm 4.83 \mathrm{mmol} / \mathrm{l}$, respectively and for the 3rd trimester, the latter values were as follows: $1.01 \pm 0.0047,7.95 \pm 0.67$ and $1.6 \pm 1.42 \mathrm{mmol} / \mathrm{l}$, respectively. In both, 2nd and 3rd trimester sub-groups, the correlation between glucose concentration and week of pregnancy is negative, and there is also a relation between glucose concentration and $\mathrm{pH}$ value (Tab. 1). The test manufacturer declares there is no dependence among $\mathrm{pH}$ and glucose parameters.

Tab. 1. Correlation analysis of studied parameters with values expressed as Pearsons correlation coefficient $r$.

\begin{tabular}{|c|c|c|c|c|c|c|c|c|c|}
\hline & \multicolumn{3}{|c|}{ Whole group $(n=89)$} & \multicolumn{3}{|c|}{ 2nd trimester $(\mathrm{n}=68)$} & \multicolumn{3}{|c|}{ 3rd trimester $(\mathrm{n}=21)$} \\
\hline & WoP & $\mathrm{pH}$ & SG & WoP & $\mathrm{pH}$ & SG & WoP & $\mathrm{pH}$ & SG \\
\hline \multirow{2}{*}{$\mathrm{pH}$} & -0.27 & 1 & & -0.21 & 1 & & -0.00 & 1 & \\
\hline & $* *$ & & & NS & & & NS & & \\
\hline \multirow{2}{*}{ SG } & -0.46 & 0.19 & 1 & 0.21 & 0.15 & 1 & -0.46 & -0.24 & 1 \\
\hline & $* * *$ & NS & & NS & NS & & $*$ & NS & \\
\hline \multirow{2}{*}{ Glu } & -0.43 & 0.33 & 0.14 & -0.25 & 0.25 & -0.09 & -0.48 & 0.53 & 0.31 \\
\hline & & $* *$ & NS & $*$ & $*$ & NS & $*$ & $*$ & NS \\
\hline
\end{tabular}

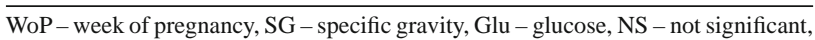
${ }^{*} \mathrm{p}<0.05,{ }^{* *} \mathrm{p}<0.01,{ }^{* * *} \mathrm{p}<0.001$

Tab. 2. Statistical analysis of selected parameters in nitrite negative vs nitrite positive amniotic fluid samples (based on T-test).

\begin{tabular}{llcccc}
\hline Nitrites reaction & WoP & SG & pH & Glu \\
\hline \multirow{4}{*}{$\mathrm{N}-$} & Max & 24 & 1.03 & 9 & 17 \\
& Min & 17 & 1.005 & 7 & 2.8 \\
& Median & 18 & 1.015 & 8 & 2.8 \\
& Average & 18.98 & 1.016 & 8.17 & 5.33 \\
& SD & 1.93 & 0.0067 & 0.62 & 4.51 \\
\hline \multirow{4}{*}{$\mathrm{N}+$} & Max & 24 & 1.03 & 9 & 17 \\
& Min & 16 & 1.01 & 8 & 2.8 \\
& Median & 18.5 & 1.02 & 9 & 5.5 \\
& Average & 19 & 1.022 & 8.62 & 6.67 \\
F test & SD & 2.04 & 0.0047 & 0.50 & 5.29 \\
\hline \multirow{2}{*}{ T test } & & 0.74 & 0.062 & 0.23 & 0.36 \\
& & 0.96 & 0.00015 & 0.0027 & 0.27 \\
\hline
\end{tabular}

WoP - week of pregnancy, SG - specific gravity, Glu - glucose, NS - not significant,* $\mathrm{p}<0.05,{ }^{* *} \mathrm{p}<0.01, * * * \mathrm{p}<0.001$ 
Within the whole group of samples $(\mathrm{n}=89)$, nitrites were positive in $29 \%(n=26 ; N+)$ and negative in $71 \%(n=63 ; N-)$. N+ samples were only in the sub-group of 2 nd trimester $(n=68)$, where $62 \%(n=42)$ were $\mathrm{N}-$ and $38 \%(n=26)$ were $\mathrm{N}+$. A T-test shows a significant difference in specific gravity $(\mathrm{p}=0.00015)$ and $\mathrm{pH}$ values ( $\mathrm{p}=0.0027$ ) between the $\mathrm{N}+$ sub-group and $\mathrm{N}$ - sub-group when taking into account only the results from samples obtained in 2nd trimester (Tab. 2).

\section{Discussion}

Biophysical and biochemical analyses of amniotic fluid are helpful in evaluating foetal anatomy, maturity and comfort status as well as in the detection of foetal growth and abnormalities. At the beginning of pregnancy, AF is light yellow. During delivery it becomes more white and milky. The reason for this is that the amniotic fluid at the time of birth is suddenly moved, such that its viscous constituents enable it to combine with the oleaginous substances which cover the surface of the foetus, whereby it naturally becomes milky and opaque. Our result confirms the observation of Orsted et al (7) and Gupta et al (8) that near-term AF gains a colour of pale straw due to the presence of exfoliated lanugo and epidermal cells from the fetal skin or may be turbid due to the presence of vernix caseosa $(7,8)$. The specific gravity of amniotic fluid was established more than hundred years ago in range of 1.002-1.028. The specific gravity of pure amniotic fluid at the end of pregnancy averages out at 1.0078 and never rises above 1.010. The admixture of meconium always causes an increase in the specific gravity (9). The concentration of many compounds changes dramatically during pregnancy. In the tested period from 17-40 weeks the strip-determined specific density was in range of 1.000-1.030 and decreased significantly during the week of pregnancy (Fig. 1), which is in agreement with previous low values at the end of pregnancy reported in the literature, but not with the fact that amniotic fluid is less transparent at the end of pregnancy. Amniotic fluid $\mathrm{pH}$ is usually affected by foetal and maternal variables. Established $\mathrm{pH}$ values were $8(53 \%, \mathrm{n}=47)$ or 9 ( $36 \%, n=32)$, and only $11 \%(n=10)$ of samples had a $\mathrm{pH}$ value of 7. Between $\mathrm{pH}$ values and week of pregnancy is a significant negative correlation (Fig. 1). The value of $\mathrm{pH}$ positively correlates with glucose concentration and is higher in $\mathrm{N}+$ sub-group of $\mathrm{AF}$ samples (Tabs 1 and 2). Jauniax and Gulbis (5) reported a $\mathrm{pH}$ value of 7.42 for the first trimester, with a significant decrease between 11 and 14 weeks compared with the $\mathrm{pH}$ from 7 to 10 weeks, which is a slightly lower value than we have obtained. The alkaline $\mathrm{pH}$ value of amniotic fluid is probably based on a higher permeability through non-keratinized embryonic skin following the accumulation of basic substances and from the metabolism of organic anions in the embryonic tissues. The changes in acid-base balance at the end of the first trimester may correspond to the switch from mesonephros to metanephros in the maturing kidneys (6). According to Oliveira et al (9), a decreasing profile of glucose and good correlation with creatinine and gestational age suggest that glucose is a good indicator of renal maturation. The study of foetal kidney development during embryogenesis as well as knowledge of the functioning of various cellular transporters during gestation can provide important information about the physiology and pathophysiology of many syndromes that occur during gestation (9). In the study of Koski et al (10), the Pearson correlation coefficients showed a positive association between amniotic fluid glucose and maternal and foetal liver glycogen and foetal weight. These findings showed that amniotic fluid can be modified by maternal diet, and they suggested that the composition of amniotic fluid might be used as an accessible nutritional indicator of carbohydrate status in the developing foetus (10). Oliveira et al (9) noticed that the glucose concentration from the amniotic fluid decreases gradually during pregnancy. Similarly, Wallach (11) mentioned that the glucose level in amniotic fluid in the last pregnancy trimester is decreased, and the values for glucose in the amniotic fluid can be correlated with those in the blood from the navel cord, because the substances present in the amniotic fluid are excreted by the foetus and implicated in its metabolism (12). Our results showed significantly decreasing levels of glucose during pregnancy (Fig. 1). The importance of determining glucose in amniotic fluid was also increased owing to the studies of Kirshon et al (13) and Romero et al (14), which focused on the determination of glucose concentration in amniotic fluid as a value in the diagnosis of intraamniotic infection. Their results showed that higher levels of glucose are connected with bacterial infection $(13,14)$. Amniotic fluid glucose concentration is a very sensitive marker in predicting chorioamnionitis. Dildi et al (15) determined AF fluid glucose concentration, and their results showed that glucose level was better in predicting clinical chorioamnionitis than positive amniotic fluid culture results are. Gestational age-dependent normal ranges and pathologic conditions that may alter amniotic fluid glucose concentrations should be considered when interpreting amniotic fluid glucose values to diagnose microbial invasion of the amniotic cavity (15). The presence of nitrates is also connected with pathological conditions, with the presence of bacteria able to reduce nitrates. Dekaphan detection strips are mainly designed for quick urine analysis. The determination of nitrites is strictly associated with the activity of nitrate-reducing bacteria, which are able to convert endogenous nitrates into nitrites. The test is based on a modified Griess reaction, forming sodium nitrite. The colouration of the pad in not quantitatively proportional to the number of present bacteria. The evidence of nitrites by a quantitative rapid stick test in amniotic fluid thus provides interesting information, because up to $43 \%$ of amniotic fluids were nitrite positive, and all the latter cases were under the 25th week of pregnancy (Tab. 2). Sample collection lasted more than 15 months and the amniocentesis procedure followed conventional aseptic conditions. Accidental bacterial contamination and intraamniotic infections were rejected as causes of such a high percentage of positive samples, and we assume another source of nitrites present in amniotic fluid. Nitrates and nitrites naturally originating from vegetables and diet, as in processed meat, undergo enterosalivary circulation in the human body. They are recirculated in the blood, concentrated in the salivary glands, secreted in saliva and reduced to nitrites by facultative Grampositive anaerobes (Staphylococcus sciuri and S. intermedius) on 


\section{5-179}

the tongue. Owing to the acidic stomach environment, the salivary nitrites are reduced to large quantities of nitric oxide (NO) and other oxides of nitrogen (16). NO is a potent vasodilator which plays a key role in the control of vascular tone and is released by endothelial cells from L-arginine. During normal pregnancy, uterine and systemic vascular functions change dramatically. Foetoplacental circulation is maintained maximally dilated, and low resistance is necessary for foetal health and growth (17). The information about NO metabolites comes mainly from blood samples. In their study, Yang et al (1996) noted that increased nitrate concentrations in maternal and foetal circulations may reflect increased NO synthesis, which may in part mediate the cardiovascular adaptations to normal pregnancy and low systemic and umbilical vascular resistance in the foetus (18). The impairment in nitric oxide production has been proposed as a possible mechanism for reducing foetoplacental circulation in pregnancy complications associated with vasospasm, such as preeclampsia (19). Pisaneschi et al (2012) recently made some interesting novel findings on blood samples, showing evidence of increased $\mathrm{NO}_{2}$ production during pregnancy and after birth in foetal growth restriction. In addition, the authors found the adjustment of the NO system in a mode of impaired vascular resistance. This adaptive response within and outside the placenta is associated with changes in 26 genes controlling blood flow, angiogenesis, extracellular matrix remodelling and inflammation and persists after birth (20). Because of lack of innervation, placenta circulation is mainly regulated by the action of vasoactive substances (21). Nakatsuka et al (22) studied the total nitrite and nitrate concentration in vaginal secretions as a predictor of premature delivery. In patients with preterm premature rupture of membranes and in patients with preterm labour and subsequent premature delivery these were significantly higher than the concentrations in patients who delivered at term. There is evidence that NO is also released by the foetoplacental tissues (23), and there are a few studies oriented on the determination of nitrites in amniotic fluid and its possible applications. The concentration of NOx increases during pregnancy and is not related to foetal haemolysis (24). Morris et al (1995) assessed exhaled maternal NO concentration and amniotic fluid nitrite concentration between 10th to 42nd week of pregnancy. While exhaled NO concentrations did not alter significantly during gestation, there was, conversely, a significant change in amniotic fluid nitrite concentration in late pregnancy ( $\mathrm{p}<0.001$ ). The finding of decreased amniotic nitrite concentrations after 37th week of gestation (Tab. 2) supports the hypothesis that reduced NO production may contribute to increased uterine activity in late pregnancy (25). Di Iorio et al (19) determined nitric oxide metabolites $\left(\mathrm{NO}^{2-}\right.$ and $\left.\mathrm{NO}^{3-}\right)$ in amniotic fluid to examine their relation to uteroplacental blood flow and reported that higher overall nitrite values in amniotic fluid $(\mathrm{p}<0.01)$ in intrauterine growth retarded the patients more than the controls. A significant negative correlation was observed between nitrite concentrations and the uterine artery resistance index, umbilical artery pulsatility index and umbilical artery pulsatility index/middle cerebral artery pulsatility index ratio (19). Hsu et al (26) presented a rare application of nitrites determination in amniotic fluid. In preterm labour pa- tients, they determined higher NO metabolites (NOx: nitrate + nitrite), namely in women with an intraamniotic infection ( $\mathrm{n}=$ $13)$ compared with those without infection $(n=24)$. The concentration positively correlated to the amniotic fluid PGE2 concentration (26). Later (1999), the authors extended the findings to the effect that NOx concentrations are significantly higher in patients with a positive culture $(\mathrm{n}=8)$ but are not caused by a mycoplasma agent ( $n=7)$ compared with controls (61) (27). Among amniotic fluid samples in our group of patients only one was diagnosed with intrauterine growth retardation in the 26th week with a nitrite-negative result.

\section{Conclusion}

Our study investigated the direct measurements of some basic chemical and physical properties of amniotic fluid samples. Our results show a negative correlation between the week of gestation, specific gravity, and $\mathrm{pH}$ which is in accordance with the foetal kidneys development and skin keratinization. Our results also show a negative correlation between the glucose concentration and pregnancy week. The glucose values are in correlation with the foetal growth and development, and on the other hand the determination of glucose is important because the level of glucose seems to be a very good predictive marker in clinical diagnosis of chorioamnionitis, and microbial invasion of the amniotic cavity. Our finding that nitrite concentrations are decreasing in amniotic fluid after 37th gestation week supports the hypothesis that reduced NO production may contribute to increased uterine activity in late pregnancy. Results obtained in this study could be useful as a baseline for monitoring changes in the intrauterine environment in normal and abnormal pregnancies. Based on significant contributions of AF to foetal and neonatal health, additional research is needed to better understand its functions and to correct its disorders.

\section{References}

1. Underwood MA, Gilbert WM, Sherman MP. Amniotic fluid: not just fetal urine anymore. J Perinat 2005; 25: 341-348.

2. Akinbi HT, Narendran V, Pass AK, Markart P, Hoath SB. Host defense proteins in vernix caseosa and amniotic fluid. American Journal of Obstetrics and Gynecology 2004; 191: 2090-2096.

3. Modena AB, Fieni S. Amniotic fluid dynamics. Acta Biomed 2004; 75: $11-13$.

4. The fetus.net (Internet). Moghazy, M. Amniotic fluid dynamic. Dynamic. 2007, Available from http://sonoworld.com/fetus/page.aspx?id=2463.

5. Jauniaux E, Gulbis B. Fluid compartments of the embryonic environment. Human Reprod Update 2000; 6: 268-278.

6. Jauniaux E, Jurkovic D, Gulbis B, Collins WP, Zaidi J, Campbell S. Investigation of the acid-base balance of coelomic and amniotic fluids in early human pregnancy. Amer J Obstet Gynec 1994; 170: 1365-1369.

7. Orsted HC. Selected Scientific Works of Hans Christian Orsted. Princeton University Press, 2014: 1 - 688.

8. Gupta SA. Comprehensive Textbook of Obstetrics and Gynecology. JP Medical Ltd, 2011: 1 - 651. 
9. Oliveira FR, Barros EG, Magalhães JA. Biochemical profile of amniotic fluid for the assessment of fetal and renal development. Brazil J Med Biol Res 2002; 35: 215-222.

10. Koski KG, Fergusson MA. Amniotic fluid composition responds to changes in maternal dietary carbohydrate and is related to metabolic status in term fetal rats. J Nutrit 1992; 122: 385-392.

11. Wallach JB. The interpretation of clinical diagnosis tests. Lippincott Williams \& Wilkins Publishers, 2000: 1 - 620.

12. Liteanu A, Martiniuc V, Gorduza V, Artenie V. Some biochemical indicators of the amniotic fluid - possible way for evaluation of the renal development. Analele Stiintifice Ale Universitatii “Al.I.Cuza” Din Iasi. (Serie Noua).Sectiunea 2.a.Genetica Si Biologie Moleculara, 2009, 10 (4). www://search.proquest.com/docview/1032650626?accountid=16775

13. Kirshon B, Rosenfeld B, Mari G, Belfort, M. Amniotic fluid glucose and intraamniotic infection. Amer J Obstet Gynec 1991; 164: 818-820.

14. Romero R, Jimenez C, Lohda AK, Nores J, Hanaoka S, Avila C, Callahan R, Mazor M, Hobbins JC, Diamond MP. Amniotic fluid glucose concentration: a rapid and simple method for the detection of intra amniotic infection in preterm labor. Amer J Obstet Gynec 1990; 163: 968-974.

15. Dildy GA, Pearlman MD, Smith LG, Tortolero-Luna G, Faro S, Cotton DB. Amniotic Fluid Glucose Concentration: A Marker for Infection in Preterm Labor and Preterm Premature Rupture of Membranes. Infect Dis Obstet Gynec 1994; 1: 166-172.

16. McKnight GM, Duncan CW, Leifert C, Golden MH. Dietary nitrate in man: friend or foe? Brit J Nutrit 1999; 81: 349-358.

17. Gant N, Daley G, Chand S, Whalley P, MacDonald P. A study of angiotensin I1 pressor response throughout primigravid pregnancy. J Clin Invest 1973; 52: 2682-2689.

18. Yang D, Lang U, Greenberg SG, Myatt L, Clark KE. Elevation of nitrate levels in pregnant ewes and their fetuses. Amer J Obstet Gynec 1996; 174: 573-577.
19. di Iorio R, Marinoni E, Coacci F, La Torre R, Cosmi EV. Amniotic fluid nitric oxide and uteroplacental blood flow in pregnancy complicated by intrauterine growth retardation. Brit J Obstet Gynaec 1997; 104: 1134-1139.

20. Pisaneschi S, Strigini FAL, Sanchez AM, Begliuomini S, Casarosa E, Ripoli A, Ghirri P, Boldrini A, Fink B, Genazzani AR, Coceani F, Simoncini T. Compensatory Feto-Placental Upregulation of the Nitric Oxide System during Fetal Growth Restriction. PLoS ONE 2012; 7 (9): e45294.

21. Chervenak FA, Kurja A. Fetal medicine, USA:CRC Press, CRC Press, 1999: 1 - 402

22. Nakatsuka M, Habara T, Kamada Y, Tada K, Kudo T. Elevation of total nitrite and nitrate concentration in vaginal secretions as a predictor of premature delivery. Amer J Obstet Gynec 2000; 182: 644-645.

23. Myatt L, Eis AL, Brockman DE, Greer IA, Lyall F. Endothelial nitric oxide synthase in placental villous tissue from normal, pre-eclamptic and intrauterine growth restricted pregnancies. Human Reprod 1997; 12: 167-172.

24. Egberts J, van den Bosch N, Soederhuizen P. Amniotic fluid nitric oxide metabolites, cyclic guanosine 3',5' monophosphate and dimethylarginine in alloimmunized pregnancies. Eur J Obstet Gynec Reprod Biol 1999; 85: 209-214.

25. Morris NH, Carroll S, Nicolaides KH, Steer PJ, Warren JB. Exhaled nitric oxide concentration and amniotic fluid nitrite concentration during pregnancy. Eur J Clin Invest 1995; 25: 138-141.

26. Hsu CD, Meaddough E, Aversa K, Hong SF, Lee IS, Bahodo-Singh RO, Lu LC, Copel JA. Dual roles of amniotic fluid nitric oxide and prostaglandin E2 in preterm labor with intra-amniotic infection. Amer J Perinat 1998; 15:683-687.

27. Hsu, CD, Aversa KR, Lu LC, Meaddough E, Jones D, BahadoSingh RO, Copel JA, Lee IS. Nitric oxide: a clinically important amniotic fluid marker to distinguish between intra-amniotic mycoplasma and nonmycoplasma infections. Amer J Perinat 1999; 16: 161-166. 